\title{
Influence of propulsion efficiency on contrail formation
}

\author{
Ulrich Schumann* \\ Deutsches Zentrum für Luft- und Raumfahrt (DLR), Institut für Physik der Atmosphäre, Oberpfaffenhofen, Postfach 1116, \\ 82230 Wessling, Germany
}

Received 19 January 2000; revised and accepted 22 May 2000

\begin{abstract}
Aircraft cause contrails when flying in an atmosphere colder than a threshold temperature which depends on the overall efficiency $\eta$ of propulsion of the aircraft/engine combination. Higher $\eta$ causes contrails at higher ambient temperatures and over a larger range of flight altitudes. The ratio of temperature increase relative to moisture increase in engine plumes is lower for engines with higher $\eta$. Thermodynamic arguments are given for this fact and measurements and observations are reported which support the validity of the given criterion. The measurements include contrail observations for identified aircraft flying at ambient temperature and humidity conditions measured with high precision in-situ instruments, measurements of the temperature and humidity increases in an aircraft exhaust plume, and an observation of contrail formation behind two different four-engine jet aircraft with different engines flying wing by wing. The observations show that an altitude range exists in which the aircraft with high efficiency causes contrails while the other aircraft with lower efficiency causes none. Aircraft with more efficient propulsion cause contrails more frequently. The climatic impact depends on the relative importance of increased contrail frequency and reduced carbon dioxide emissions for increased efficiency, and on other parameters, and has not yet been quantified. C 2000 Éditions scientifiques et médicales Elsevier SAS

contrail / aircraft propulsion / efficiency / atmosphere

Zusammenfassung

Einfluss des Antriebswirkungsgrades auf die Bildung von Kondensstreifen. Kondensstreifen bilden sich hinter Flugzeugen, die in einer Atmosphäre fliegen, die kälter ist als eine Grenztemperatur, deren Wert vom Antriebs-Gesamt-Wirkungsgrad $\eta$ der Flugzeug/Triebwerks-Kombination abhängt. Für größeres $\eta$ entstehen Kondensstreifen bei höheren Umgebungstemperaturen und über einen größeren Höhenbereich. Die Zunahme der Temperatur im Vergleich zur Feuchte im Abgas ist um so kleiner je größer $\eta$ ist. Die thermodynamischen Gründe hierfür werden erklärt und es werden Messungen und Beobachtungen berichtet, die diese Zusammenhänge bestätigen. Die Messungen umfassen Beobachtungen von Kondensstreifen hinter bekannten Flugzeugen mit genauen lokalen Messungen der Temperatur und Feuchte der Atmosphäre im Flugniveau, Messungen der Temperatur- und Feuchtedifferenz zwischen Abgasfahne und Umgebung, und Beobachtungen des Einsetzens von Kondensstreifen hinter zwei dicht nebeneinander fliegenden vierstrahligen Strahlflugzeugen mit verschiedenen Triebwerken. Die Beobachtungen belegen, dass es einen Höhenbereich gibt, in dem nur das Flugzeug mit hohem Wirkungsgrad einen Kondensstreifen bildet. Verbesserungen des Antriebs-Gesamt-Wirkungsgrades führen zu mehr Kondensstreifen. Der damit verbundene Klimaeinfluss hängt außer von den vermehrten Kondensstreifen auch von den verminderten Beiträgen zu Kohlendioxid in der Atmosphäre bei effektiveren Flugzeugen ab und von weiteren Parametern und ist bisher nicht quantifiziert. (C) 2000 Éditions scientifiques et médicales Elsevier SAS
\end{abstract}

Kondensstreifen / Flugzeug-Antrieb / Wirkungsgrad / Atmosphäre

*E-mail: ulrich.schumann@dlr.de 


\section{Nomenclature}

\begin{tabular}{|c|c|}
\hline$c_{\mathrm{p}}$ & specific heat capacity of air at constant pressure \\
\hline C & $c_{p} \Delta q / \Delta h_{p}$, contrail factor \\
\hline$e$ & water vapour partial pressure \\
\hline$e_{\text {sat }}$ & water vapour saturation pressure over liquid water \\
\hline$E I_{\mathrm{H}_{2} \mathrm{O}}$ & $\begin{array}{l}\text { water emission index: mass of water emitted per } \\
\text { mass of fuel burnt }\end{array}$ \\
\hline$F$ & thrust \\
\hline$G$ & $\Delta e / \Delta T$, slope of the mixing line \\
\hline$h_{\mathrm{p}}$ & $=h+1 / 2\left(V_{\mathrm{p}}-V\right)^{2}$, mass specific plume enthalpy \\
\hline$h_{\mathrm{t}}$ & $=h+1 / 2 V_{\mathrm{p}}^{2}$, mass specific total enthalpy \\
\hline$V$ & true air speed \\
\hline$\dot{m}_{\mathrm{f}}$ & fuel mass flow rate \\
\hline$\dot{m}_{\mathrm{j}}$ & mass flow rate through engine \\
\hline$p$ & pressure \\
\hline$q$ & water vapour mass concentration \\
\hline$Q$ & combustion heat of fuel \\
\hline SFC & $=\dot{m}_{\mathrm{f}} / F$, specific fuel consumption \\
\hline$T$ & temperature \\
\hline$T_{\mathrm{C}}$ & threshold temperature for contrail formation \\
\hline$V_{\mathrm{j}}, V_{\mathrm{p}}$ & speeds of jet and plume air \\
\hline$\Delta e$ & $\begin{array}{l}\text { water vapour partial pressure difference between } \\
\text { plume and ambient air }\end{array}$ \\
\hline$\Delta T$ & $\begin{array}{l}\text { temperature difference between plume and ambient } \\
\text { air }\end{array}$ \\
\hline$\varepsilon$ & $\begin{array}{l}=R_{\text {air }} / R_{\mathrm{H}_{2} \mathrm{O}}=0.622 \text {, ratio of gas constants of air } \\
\text { and water vapour }\end{array}$ \\
\hline$\eta$ & $=F V /\left(\dot{m}_{\mathrm{f}} Q\right)$, overall efficiency \\
\hline \multicolumn{2}{|l|}{ Indices } \\
\hline $\mathrm{e}, \mathrm{E}$ & environmental \\
\hline $\mathrm{f}$ & fuel \\
\hline $\mathrm{j}$ & jet \\
\hline $\mathrm{p}$ & plume \\
\hline $\mathrm{C}$ & critical (threshold) \\
\hline M & maximum \\
\hline
\end{tabular}

\section{Introduction}

The Special Report of the Intergovernmental Panel on Climate Change (IPCC) on 'Aviation and the Global Atmosphere' [10] notes that engine efficiency improvements reduce the specific fuel consumption and, hence, most types of emissions, but contrails may increase. It also notes that contrail cover is projected to grow faster than aviation fuel consumption in the long-term future, partly because future aircraft will have higher propulsion efficiency. These statements are explained in chapter 3 of that report [7] and papers cited therein. The statements were highly debated during the final acceptance procedure of the report and not all critics could be convinced that they are correct. Therefore this paper explains the basic thermodynamic arguments behind these statements and reports on recent experiments which support the theory.
The overall efficiency of propulsion [5] is the ratio

$$
\eta=F V /\left(\dot{m}_{\mathrm{f}} Q\right)
$$

between the work rate $F V$ performed by the thrust $F$ of the engine at air speed $V$ relative to the amount of chemical energy $\dot{m}_{\mathrm{f}} Q$ provided by the fuel with specific combustion heat $Q$ at flow rate $\dot{m}_{\mathrm{f}}$. The value of $Q$ varies little between aviation fuels, and $V$ as well as the specific fuel consumption $\mathrm{SFC}, \mathrm{SFC}=\dot{m}_{\mathrm{f}} / F$ [5], are often published by engine manufacturers. Since the overall efficiency depends on speed $V$, and the thrust $F$ balances the aircraft drag, it is actually not a parameter of the engine alone but characterises the engine/aircraft combination and its state of operation.

Contrails form, if, during mixing the plume gases become saturated with respect to liquid water. Contrails form at temperatures below a threshold temperature which is higher the steeper the mixing line in a diagram of water vapour partial pressure $e$ versus temperature $T$, see figure $1[2,28]$. The slope $G$ of the mixing line is the larger the higher $\eta$, and hence propulsion efficiency influences contrail formation [31].

The importance of the split of combustion heat into work to propel the aircraft and heat that warms the exhaust plume was first noted by Schmidt [28], and later by others $[14,17,19,25]$. Peters [23] found that contrails were observed under conditions where the classical Appleman criterion predicts that no contrails should appear. He found empirically that observations fit the thermodynamic explanation better when assuming different contrail parameters related to $G$ for low, medium and high bypass engines, without detailed thermodynamic reasoning. Engine-type dependent contrail factors were later also used by several other authors $[4,8,21,29,30$, 38]. Busen and Schumann [3] were the first who showed experimentally the ' $\eta$-effect', i.e., that observed contrail

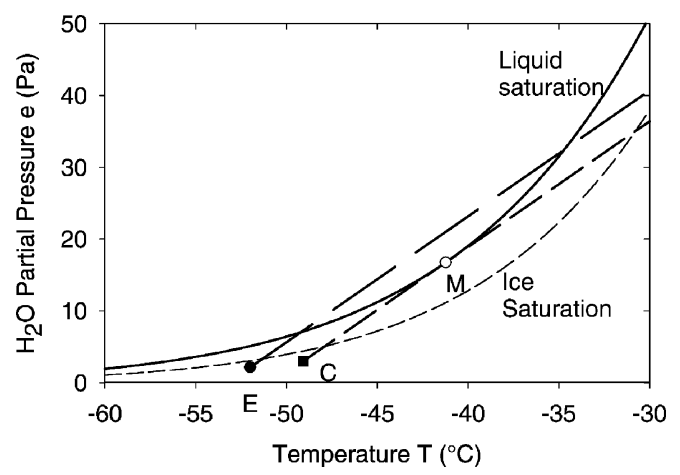

Figure 1. Mixing lines (dashed) and saturation curve over liquid water (full) in a diagram of partial water vapour pressure $e$ versus temperature $T$. The mixing lines are plotted for environmental conditions with environmental temperature $T_{\mathrm{e}}$ below (point $\mathrm{E}$ ) and at (point $\mathrm{C}$ ) the threshold temperature. The point $\mathrm{M}$ is that of maximum relative humidity during mixing under threshold conditions. 
formation can be explained when accounting for the fact that only the fraction $(1-\eta)$ of the combustion heat contributes to warming the air in the aircraft plume where contrails form, and they showed that $\eta$ and hence $G$ depends not only on the type of engine but also on the drag and speed of the aircraft.

The overall efficiency $\eta$ was close to 0.2 in the $1950 \mathrm{~s}$, near 0.3 on average for the subsonic airliner fleet in 1992, and may reach 0.5 for new engines to be built by $2010[10,15]$. The efficiency is 0.35 for a B747 aircraft with CF6-80C2B1F engines cruising with Mach 0.86 at $11.9 \mathrm{~km}$ altitude, and 0.40 for a Concorde with Olympus 593 engines cruising with Mach 2 at $16.5 \mathrm{~km}$, on 6400 $\mathrm{km}$ missions [6].

The $\eta$-effect is important because it implies that better engines, though using less fuel for the same propulsive thrust (i.e. less SFC), do produce contrails at higher ambient temperatures and hence at lower altitudes in the troposphere and larger altitudes in the stratosphere, i.e. over a larger range of altitudes.

The disturbances induced by global aviation cause an additional radiative forcing (heating) of the Earthatmosphere-system by aircraft of about $0.05 \mathrm{~W} \mathrm{~m}^{-2}$ or about $3.5 \%$ of the total radiative forcing by all anthropogenic activities in 1992. The accumulated carbon dioxide emissions from aviation until 1992 and the contrail cover in 1992 have been estimated to have contributed both about $0.02 \mathrm{~W} \mathrm{~m}^{-2}$ while nitrogen oxides emissions (by changing ozone and methane concentrations) contributed the rest. These values are increasing because of increasing air traffic causing more contrail cover and increasing aircraft emissions [10,26]. Of climatic importance are only the long-lasting contrails which form in ice-saturated ambient air, mainly in the upper troposphere $[9,11,20,27,31]$.

The $\eta$-effect is of quantitative importance in assessing the climatic effects from contrails. In the troposphere, an increase of $\eta$ from 0.3 to 0.5 in the standard atmosphere increases the threshold formation temperature of contrails by 4.2 to $4.9 \mathrm{~K}$ (increasing with ambient humidity), equivalent to 650 to $760 \mathrm{~m}$ lower threshold altitude [31]. In the stratosphere, the same change in $\eta$ increases the formation temperature even more (by $14 \mathrm{~K}$ ), equivalent to $2130 \mathrm{~m}$ higher altitude (for zero ambient humidity, and $-56.5^{\circ} \mathrm{C}$ ambient temperature, the altitude is 13.8 and $15.9 \mathrm{~km}$ for $\eta=0.3$ and 0.5 , respectively). However contrails remain usually short in the very dry stratosphere.

In a fuel consumption scenario of 1992, the global mean contrail cover is computed to amount to about $0.1 \%$ for $\eta=0.3$, and changes by $10 \%$ of this value if $\eta$ varies from 0.25 to 0.35 [27]. The contrail cover reacts to $\eta$ more strongly locally than globally. In a baseline scenario of traffic and fuel consumption development from 1992 to 2050 used in IPCC [10], traffic increases by a factor of about 6 , fuel consumption by a factor of about 3.2, fuel consumption in the upper troposphere (where contrails form preferentially) by a factor of about
4 , contrail cover by a factor of 5 , and radiative forcing by a factor of about 6 . The about 3 -fold increase in fuel consumption from 1992 to 2050 causes a 6-fold increase in the radiative forcing by contrails because of increase of fuel consumption (factor 3.2), relatively stronger increase of fuel consumption in the upper troposphere (factor 1.36), more contrail cover because of more efficient engines (factor 1.24), and because more traffic will occur in regions with high specific forcing per contrail cover (factor 1.11) $[9,20]$. Hence propulsion efficiency is responsible for $20 \%(0.24 / 1.24)$ of the expected future increase in contrail cover and radiative forcing. In this paper, the theory of the $\eta$-effect is explained and data are presented supporting the theory.

\section{Contrail formation conditions}

The exhaust heat and the mass of exhaust gases leaving the engine are contained within a region called 'plume' which grows in cross-section by mixing with ambient air. The young plume coincides with the 'jet' of high speed exhaust gases which forms initially by merging the jet from the core engine and the jet of air passing through the fan in the engine bypass surrounding the core engine, see figure 2. At engine exit, temperature and humidity profiles of the core and bypass jets are much different, because the core jet contains a large fraction of the combustor heat and all of the water vapour formed resulting from burning the hydrocarbon fuel with air while the bypass jet carries part of the heat but no combustion water vapour, and the jets have different velocities. After engine exit, the jets expand to outside pressure and approach isobaric conditions. A few engine diameters after engine exit, possibly depending on whether the bypass and core jets are premixed internally in an engine with shrouded bypass, a uniform turbulent jet forms in which the temperature and humidity profiles

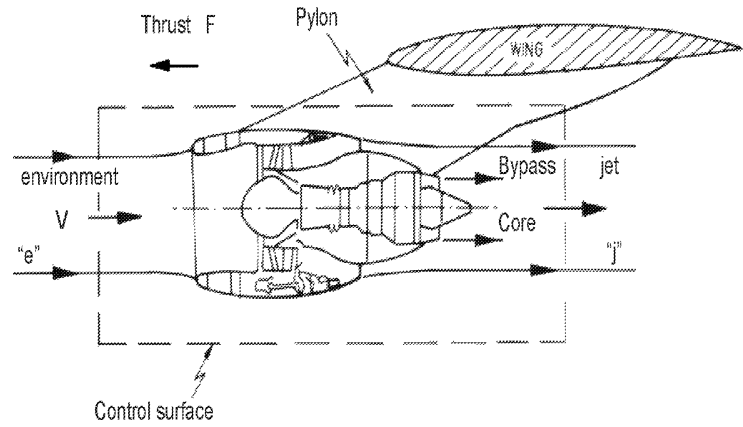

Figure 2. Control surface surrounding the engine, with environmental air $(e)$ at entry (speed $V$ ), and core and bypass jets combining into one jet with jet speed $V_{\mathrm{j}}$ at the downstream exit plane $(j)$ of the control volume. The static pressure is assumed to be constant at the control surface. The engine transfers thrust $F$ to the wing via the pylon. (adapted from [5], with the author's permission). 
approach a similar shape. Numerical simulations have shown that the remaining differences in the temperature and humidity profiles may enhance the maximum relative humidity reached in the plume by about $10 \%$ and the threshold temperature for contrail formation by about $1 \mathrm{~K}$ [33]. This effect is neglected in the following analysis.

The jet carries energy initially both in the form of internal enthalpy $\mathrm{h}$ and kinetic energy per unit mass. During mixing, the specific energy $1 / 2\left(V_{\mathrm{p}}-V\right)^{2}$ due to velocity differences between the speed $V_{\mathrm{p}}$ of the jet (or plume) air and the speed $V$ of ambient air gets converted into internal enthalpy, so that the jet ceases. During this mixing process the specific plume enthalpy

$$
h_{\mathrm{p}}=h+1 / 2\left(V_{\mathrm{p}}-V\right)^{2}
$$

is a conserved property of the plume gases. The speed values refer to the frame of reference fixed to the aircraft. As a consequence of the split into two forms of energy, the plume temperature is smaller than is to be expected from the released combustion heat. In principle, this enhances the tendency for contrail formation and the corresponding threshold temperature, and the effect grows with $(1-\eta)^{2} V^{2} /\left(c_{\mathrm{p}} \eta^{2}\right)$, where $c_{\mathrm{p}}$ is the specific heat capacity of air at constant pressure [31]. However, most of the kinetic energy is converted to heat by mixing and dissipation before a contrail forms, so that the threshold temperature increases only by 0.1 to $0.2 \mathrm{~K}$ for typical airliners. Hence, to a good approximation, the plume temperature at the point where contrails form is directly related to $h_{\mathrm{p}}$, and the state of the plume during mixing with ambient air follows essentially a straight line in a water concentration-enthalpy $\left(q-h_{\mathrm{p}}\right)$ diagram from the state approximating the engine exit conditions to the state of the ambient atmosphere (e.g., point $\mathrm{E}$ in figure 1).

The mass specific water concentration $q$ is related to partial water vapour pressure $e$ in an ideal gas,

$$
e / p=q R_{\text {air }} / R_{\mathrm{H}_{2} \mathrm{O}}=q / \varepsilon, \quad \varepsilon=0.622,
$$

with given gas constants $R$ of air and water vapour. Plume enthalpy $h$ and temperature $T$ are linearly related for constant $c_{\mathrm{p}}$, which is a reasonable assumption for typical contrail conditions. Hence the mixing line is close to straight also in an $e-T$-diagram, see figure 1 . The slope of the mixing line is:

$$
G=\Delta e / \Delta T=p c_{\mathrm{p}} \Delta q /\left(\Delta h_{\mathrm{p}} \varepsilon\right) .
$$

(The ratio $C=c_{\mathrm{p}} \Delta q / \Delta h_{\mathrm{p}}$ is also known as contrail factor [2].) Here $\Delta e$ and $\Delta T$ are the differences between the values of water vapour partial pressure and temperature in the plume and the respective values in the ambient air. Figure 1 shows also the saturation pressure $e_{\text {sat }}$ of water vapour over liquid water which grows strongly with temperature $T$ [37]. The relative humidity $U=e / e_{\text {sat }}$ is very low near the engine exit and often low in the ambient atmosphere, but may reach saturation during mixing at point $\mathrm{M}$ of figure 1 when the ambient temperature $T_{\mathrm{e}}$ equals the threshold temperature $T_{\mathrm{C}}$. As can be understood from figure 1, the threshold temperature $T_{\mathrm{M}}$ for $100 \%$ relative humidity in the ambient air follows from $d e_{\text {sat }}\left(T_{\mathrm{M}}\right) / d T=G$. Its value can be evaluated with high precision for $-60^{\circ} \mathrm{C} \leqslant T_{\mathrm{M}} \leqslant-10^{\circ} \mathrm{C}$ from

$$
\begin{aligned}
T_{\mathrm{M}}= & -46.46+9.43 \ln (G-0.053) \\
& +0.720[\ln (G-0.053)]^{2},
\end{aligned}
$$

with $T_{\mathrm{M}}$ in ${ }^{\circ} \mathrm{C}$ and $G$ in $\mathrm{Pa} \mathrm{K}^{-1}$ [31]. Likewise, the threshold temperature $T_{\mathrm{C}}$ for given ambient humidity $U$ follows from:

$$
T_{\mathrm{C}}=T_{\mathrm{M}}-\left[e_{\mathrm{sat}}\left(T_{\mathrm{M}}\right)-U e_{\mathrm{sat}}\left(T_{\mathrm{C}}\right)\right] / G .
$$

This can be evaluated directly for $U=0$ or $U=1$, and with a Newton iteration otherwise (a Fortran routine for that purpose is available from the author). Other, often less accurate, approximate solutions have been proposed $[4,8,21]$.

\section{Engine energy budget}

For convenience, we consider an engine contained within a control volume fixed with boundaries far enough upstream and downstream of the engine as shown in figure 2 so that the pressure is close to uniform across the volume boundary. Moreover, we assume that the fuel mass flow rate $\dot{m}_{\mathrm{f}}$ is small compared to the mass flow rate $\dot{m}_{\mathrm{j}}$ of gases through the engine and ignore any minor energy fluxes, such as electric energy production, bleed air for aircraft heating, or heat losses from the engine other than with the jet flow. Also, we do not distinguish between core and bypass ducts and jets, rather than consider the whole engine as a black box, and assume that the engine produces a jet of exhaust gases that result from the mixed sum of bypass and core jets. These assumptions could be avoided but that would result in a more complex analysis without gain of insight and without changing the conclusions. Since the nominal air speed of the aircraft is $V$, air enters the control volume from the front (index $e$ for environmental) with speed $V$ relative to the aircraft and leaves the control volume at the rear (index $\mathrm{j}$ for jet) with speed $V_{\mathrm{j}}$. The engine performs thrust $F$, a force that propels the aircraft.

\subsection{Momentum budget}

The momentum budget gives the balance between the thrust $F$ of the engine and the momentum inflow and outflow, with different speeds but same mass flux rate $\dot{m}_{\mathrm{j}}$ :

$$
F=\dot{m}_{\mathrm{j}}\left(V_{\mathrm{j}}-V\right) .
$$


The thrust grows with the mass flux $\dot{m}_{\mathrm{j}}$ and the increase in speed of the jet compared to ambient air.

\subsection{Energy budget}

The principle of energy conservation is independent of which frame of reference is being used, but the formulation of the energy budget depends on the frame of reference because of the frame-dependence of kinetic energy.

\subsubsection{Energy budget in a frame of reference fixed to the aircraft}

In a frame of reference fixed to the aircraft, the speed of the aircraft is zero and the speed of ambient air is negative the same as the nominal air speed of the aircraft. The energy budget expresses the change in the sum of internal and kinetic energy between engine exit and entry as the result of the addition of combustion heat due to burning of fuel inside the engine at the flow rate $\dot{m}_{\mathrm{f}}$ with mass specific combustion heat $Q$. The specific enthalpies at inflow and outflow are $h_{\mathrm{e}}+1 / 2 V^{2}$ and $h_{\mathrm{j}}+1 / 2 V_{\mathrm{j}}^{2}$. Thus:

$$
\dot{m}_{\mathrm{j}}\left[h_{\mathrm{j}}-h_{\mathrm{e}}+1 / 2\left(V_{\mathrm{j}}^{2}-V^{2}\right)\right]=\dot{m}_{\mathrm{f}} Q .
$$

In this reference frame, the thrust $F$ does not change the energy budget because the engine does not move in this frame. Hence this form of energy budget is independent of $\eta$. In terms of total enthalpies, $h_{\mathrm{t}}=h+$ $1 / 2 V^{2}$, the budget reads simply:

$$
\dot{m}_{\mathrm{j}}\left[h_{\mathrm{t}, \mathrm{j}}-h_{\mathrm{t}, \mathrm{e}}\right]=\dot{m}_{\mathrm{f}} Q .
$$

This simple form is the reason why total enthalpies are popular in propulsion engineering. However, this form is not suitable for plume analysis, since $h_{\mathrm{t}}$ is not conserved in the plume during turbulent conversion of kinetic energy into internal enthalpy, because the plume mixes with ambient air and the ambient air moves relative to the frame of aircraft.

\subsubsection{Energy budget in a frame of reference fixed to the ambient air}

Alternatively, in a frame of reference fixed to the ambient air, the engine is moving and the thrust now performs work. With specific enthalpies at inflow and outflow, $h_{\mathrm{e}}$ and $h_{\mathrm{j}}+1 / 2\left(V_{\mathrm{j}}-V\right)^{2}$, follows:

$$
\begin{aligned}
\dot{m}_{\mathrm{j}} & {\left[h_{\mathrm{j}}-h_{\mathrm{e}}+1 / 2\left(V_{\mathrm{j}}-V\right)^{2}\right] } \\
& =\dot{m}_{\mathrm{f}} Q-F V=\dot{m}_{\mathrm{f}} Q(1-\eta) .
\end{aligned}
$$

Here $\eta$ is the overall efficiency, see equation (1). Therefore:

$$
\Delta h_{\mathrm{p}}=h_{\mathrm{j}}-h_{\mathrm{e}}+1 / 2\left(V_{\mathrm{j}}-V\right)^{2}=Q(1-\eta) \dot{m}_{\mathrm{f}} / \dot{m}_{\mathrm{j}}
$$

The plume enthalpy $h_{\mathrm{p}}=h+1 / 2\left(V_{\mathrm{p}}-V\right)^{2}$ is different from the total enthalpy $h_{\mathrm{t}}=h+1 / 2 V_{\mathrm{p}}^{2}$. Nevertheless, both versions of the energy budget are, of coarse, formally equivalent. One can be converted into the other by replacing $F$ by $\dot{m}_{\mathrm{j}}\left(V_{\mathrm{j}}-V\right)$, equation (7). However, for our purpose only the latter version is suitable because only $h_{\mathrm{p}}$ and not $h_{\mathrm{t}}$ is conserved during conversion of kinetic to internal enthalpy during mixing of the plume with ambient air. Only the velocity difference $1 / 2\left(V_{\mathrm{j}}-V\right)^{2}$ and not $1 / 2 V_{j}^{2}$ is converted from kinetic to internal enthalpy by turbulent mixing.

\subsection{Mass budget for water vapour}

The exhaust gases carry more water vapour than the air which enters the engine, because of combustion of hydrogen containing fuels according to $E I_{\mathrm{H}_{2} \mathrm{O}}$, the emission index, which gives the mass of water produced in the engine per mass of fuel burnt:

$$
\Delta q=q_{\mathrm{j}}-q_{\mathrm{e}}=E I_{\mathrm{H}_{2} \mathrm{O}} \dot{m}_{\mathrm{f}} / \dot{m}_{\mathrm{j}} .
$$

\subsection{Consequence for contrail parameter $G$}

As a consequence of equations (4), (11) and (12) it follows that:

$$
G=\left[\Delta q / \Delta h_{\mathrm{p}}\right] p c_{\mathrm{p}} / \varepsilon=E I_{\mathrm{H}_{2} \mathrm{O}} p c_{\mathrm{p}} /[\varepsilon Q(1-\eta)] .
$$

$G$ is independent of the mass flux ratio $\dot{m}_{\mathrm{f}} / \dot{m}_{\mathrm{j}}$ and independent of dilution with growing plume age. We see that $G$, and hence $T_{\mathrm{M}}$ and $T_{\mathrm{C}}$, equations (5) and (6) grow with the overall efficiency $\eta$. Engines with higher $\eta$ cause exhaust plumes with higher relative humidity, and hence contrails already at higher ambient temperature and more frequently.

\subsection{Discussion}

Equation (11) shows that only the fraction $(1-\eta)$ of the combustion heat $Q$ enters the exhaust plume. The remainder does not heat the young exhaust jet, but is used to overcome friction and to induce kinetic energy of turbulence and vortex motions in the airframe's boundary layer and in the wake behind the aircraft. The kinetic energy of the wake vortices gets dissipated to heat long after the contrail has formed, and the dissipation of turbulence in the turbulent boundary layer heats mainly air outside the young exhaust plume.

As a consequence of less energy in the exhaust jet, the exhaust gases of modern engines exhibit a lower ratio of $\Delta T / \Delta q$. This does not imply lower temperatures everywhere in the engines. In fact, the opposite is the case. The overall efficiency is the product of thermal and propulsive efficiencies [5]. Modern engines use combustors with higher temperatures and higher pressures, 
causing a higher thermal engine efficiency [5]. However, this fact does not contradict a lower ratio $\Delta T / \Delta q$ in the plume.

A higher overall efficiency may also result from a larger bypass ratio. The propulsive efficiency increases with the bypass ratio, i.e., ratio between the mass fluxes through the bypass duct of the engine relative to the core duct of the engine [5]. For given thrust, the speed of the jets is the smaller the larger the mass flux through the engine, and hence the smaller are the losses in terms of kinetic energy.

We note that the overall efficiency $\eta$ is zero at the ground for a fixed engine, simply because $V=0$, see equation (1). For the same reason, $h_{\mathrm{p}}$ equals $h_{\mathrm{t}}$ in that case. Hence ground measurements of engine exit conditions, after proper mixing of core and bypass jets, in terms of total enthalpy or temperatures (including kinetic energy), would always give the same ratio of $\Delta T_{\mathrm{t}} / \Delta q$, regardless of the performance of the engine.

Moreover, $\eta=0$ at flight, if the engine is idle with zero thrust for finite fuel consumption (such as during descent). Therefore contrails are expected to disappear at higher altitude during descent than they occur during ascent, and an aircraft may avoid contrail formation, at least near threshold conditions, by flying with reduced power.

From equation (13) we see that the previously defined contrail factor [2] is:

$$
\begin{aligned}
C & =c_{\mathrm{p}} \Delta q / \Delta h_{\mathrm{p}}=G \varepsilon / p \\
& =E I_{\mathrm{H}_{2} \mathrm{O}} c_{\mathrm{p}} /[Q(1-\eta)] .
\end{aligned}
$$

For $\eta=0, E I_{\mathrm{H}_{2} \mathrm{O}}=1.25, c_{\mathrm{p}}=1004 \mathrm{~J} \mathrm{~kg}^{-1} \mathrm{~K}^{-1}$, and $Q=43 \mathrm{MJ} \mathrm{kg}^{-1}$, the contrail factor is $0.0292 \mathrm{~g} \mathrm{~kg}^{-1} \mathrm{~K}^{-1}$, and certainly above $0.0277 \mathrm{~g} \mathrm{~kg}^{-1} \mathrm{~K}^{-1}$ for typical kerosene fuels (hydrogen content $>13.5 \%, E I_{\mathrm{H}_{2} \mathrm{O}}>$ 1.2, $Q<43.5 \mathrm{MJ} \mathrm{kg}^{-1}$ ). Values below this minimum, as reported in reference [30], are impossible. Peters [23] suggested values of the contrail factor of 0.036, 0.040 , and $0.049 \mathrm{~g} \mathrm{~kg}^{-1} \mathrm{~K}^{-1}$ for non-bypass, low bypass and high bypass engines. These values appear to be rather large, because they imply large $\eta$-values of $0.19,0.27,0.40$. Smaller values of $C=0.030,0.034$, and $0.039 \mathrm{~g} \mathrm{~kg}^{-1} \mathrm{~K}^{-1}$ for the various engine types were used in references $[8,21,30]$. Contrail factors for bypass engines are higher than those for non-bypass engines not because the core exit temperature is reduced by extracting some energy to turn the fan [29], but because of higher overall efficiency of bypass engines. However, $C$ is not only a function of the engine but also of the aircraft performance. Much larger contrail factors would apply for hydrogen fuels $[16,31]$.

\section{Experimental validation}

\subsection{Observed and computed threshold conditions}

The dependence of contrail formation conditions on overall propulsion efficiency has been verified to different degrees by various experiments. Several of these experiments were originally designed to investigate the impact of fuel sulphur on contrail formation, but the experiments showed that fuel sulphur has only a small impact on the threshold temperature $[7,12]$.

Busen and Schumann [3], during the German experiment SULFUR 1, observed a contrail behind the Advanced Technology Testing Aircraft System (ATTAS) jet aircraft (type VFW 614 with two Rolls-Royce/SNECMA M45H Mk501 turbofan engines with bypass ratio 3 and $32.4 \mathrm{kN}$ take-off thrust) under conditions where the classical Appleman criterion, which implies $\eta=0$, would predict that no contrail forms. They showed that the observed contrail was explainable when the Appleman criterion was extended to include the $\eta$-effect. They estimated $\eta=0.15$ for this case from measured fuel flow rate, known combustion heat, and computed thrust using engine analysis and aerodynamic drag calculations. The contrail formation temperature was observed within an accuracy of about $0.5 \mathrm{~K}$, whereas the difference in threshold temperatures for $\eta=0$ and 0.15 was about $2 \mathrm{~K}$, hence the measured agreement between observed and computed threshold conditions was significant. However, they had to rely on ambient temperature and humidity data derived from a nearby radiosounding.

Later Schumann et al. [32] repeated such observations (experiment SULFUR 2) in four cases with high precision measurements of temperature and humidity using in-situ instruments (platinum resistance thermometers and frost-point hygrometers) onboard the research aircraft Falcon following the observed contrail forming aircraft ATTAS at very close distance and at the same altitude outside the aircraft plume. Contrail formation was documented in videos and photos. In spite of large differences in the sulphur content of the different fuels burnt on the two engines, the contrail onset was observed to occur at temperatures as predicted by the theory independent of aerosol properties, including the $\eta$-effect (here $\eta=0.18$, larger than in the previous experiment because of higher speed), with an uncertainty of less than $0.4 \mathrm{~K}$.

Similar measurements were performed within the NASA project SUCCESS using the NASA-DC8 as contrail forming aircraft and for high precision measurements of ambient temperature and humidity values together with visual contrail observations from various carriers [11]. Again, the data were consistent with the theoretical explanation when taking an engine efficiency of about $\eta=0.3$ for the DC 8 .

During a further experiment, SULFUR 3, Petzold et al. [24] measured ambient conditions during contrail formation behind an Airbus A310. In this case the engine efficiency $(\eta=0.28)$ was deduced from engine analysis, 
taking into account the relatively small aircraft speed during these measurements.

During the European project POLINAT, ten widebody aircraft of types B747, DC-10 and A340 were similarly observed with respect to contrail formation and the ambient conditions were measured with the Falcon using high-precision frost-point hygrometers [22]. The engine efficiency of the cruising wide-body aircraft was estimated to be $\eta=0.33$ based on engine analysis. All these data were compiled into a figure and presented and discussed by Kärcher et al. [13]. Recently, data for two more contrail observations (behind an A340 and behind the NASA DC-8) became available during the joint SONEX/POLINAT 2 experiment from measurements with the Falcon [35].

Figure 3 extends that shown in Kärcher et al. [13] collecting all the results available up to now from the 46 case studies in which observers noted and documented whether a contrail was visible or not and in which the

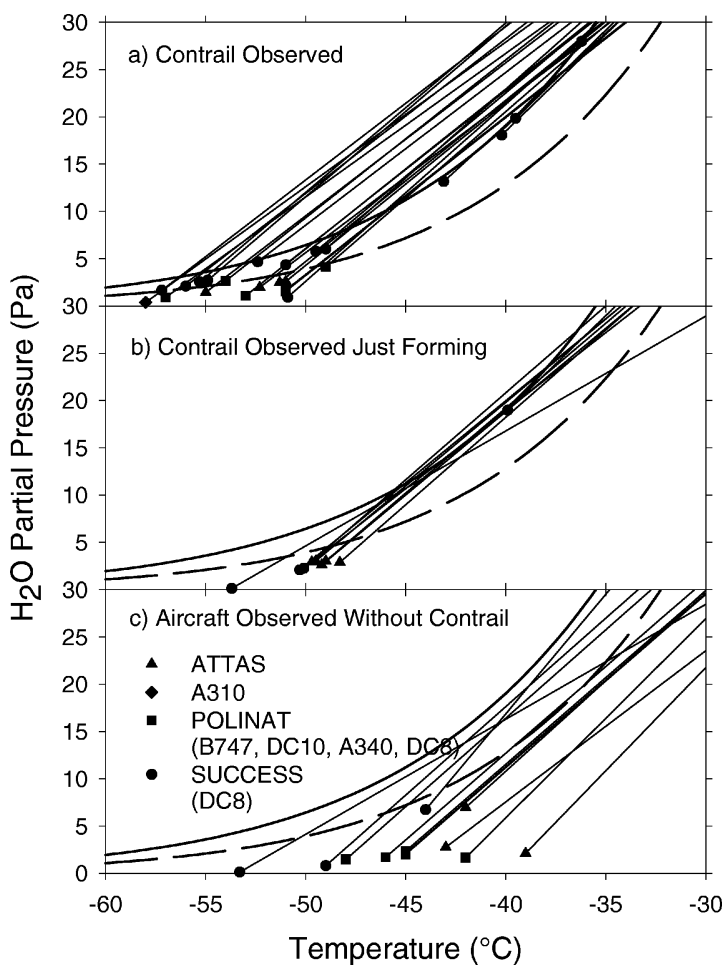

Figure 3. Water vapour partial pressure $e$ versus temperature $T$. Full thick curves: saturation pressure over liquid water, full dashed: saturation pressure over ice, symbols: measured ambient conditions for various cruising aircraft, full lines: mixing lines with gradients $G=E I_{\mathrm{H}_{2} \mathrm{O}} c_{\mathrm{p}} p[0.622 Q(1-\eta)]^{-1}$. The cases are split and presented in three panels: (a) cases where aircraft have been observed to cause visible contrails, (b) aircraft were observed with a contrail just forming or disappearing (threshold conditions), (c) aircraft were observed to fly without a visible contrail. The different symbols refer to different sets of experiments: ATTAS [32], A310 [24], POLINAT [35], SUCCESS [11]. ambient temperature and humidity was measured with high precision instruments from a research aircraft that followed the contrail forming aircraft at close distance and at the same altitude outside the aircraft plume. Moreover, the observers noted the type of aircraft and of the engines and the fuel flow rate which allowed to provide estimates of the expected overall efficiency. Symbols in figure 3 depict the measured ambient conditions and the straight lines departing from these symbols are the mixing lines. The gradient $G$ of the mixing lines is computed as a function of measured ambient pressure $p$, known values of $E I_{\mathrm{H}_{2} \mathrm{O}}$ (about 1.25) and combustion heat $Q$ (43 $\mathrm{MJ} \mathrm{kg}^{-1}$ ), specific heat capacity at fixed pressure $c_{\mathrm{p}}\left(1004 \mathrm{~J} \mathrm{~kg}^{-1} \mathrm{~K}^{-1}\right)$, and estimated overall efficiency $\eta$. Figure 3 also includes the curves of vapour pressure for saturation over liquid water (full) and ice (dashed). The cases are assigned to the three panels according to whether the observers reported that a contrail was visible (a), was just forming or disappearing (b), or that no contrail was visible behind the observed aircraft (c).

For all cases in figure 3, the mixing lines in (a) cross the liquid saturation curve as expected for contrail formation, in (b) come close to the saturation curve within the accuracy of the measured ambient conditions (better than $\pm 1 \mathrm{~K}$ in temperature and $\pm 10 \%$ in relative humidity), in (c) stay below saturation. Hence all the observed cases are explainable consistently with the given theory. This does not prove that the theory is correct (such a proof is impossible) but the fact that a large number of cases is consistent with the theory supports the assumption that the theory is correct.

Figure 4 highlights those cases where the mixing line exceeds the saturation curve over ice but where no contrails were observed. These cases show that liquid saturation is, indeed, required for contrail formation.

Figure 5 shows those cases where contrails have been observed but where the mixing line does not touch liquid saturation if computed for $\eta=0$. These cases give evidence for the fact that some contrail formation can be explained only when taking the $\eta$-effect into account, and that the classical Appleman theory, which assumes that all combustion heat gets discharged into the exhaust

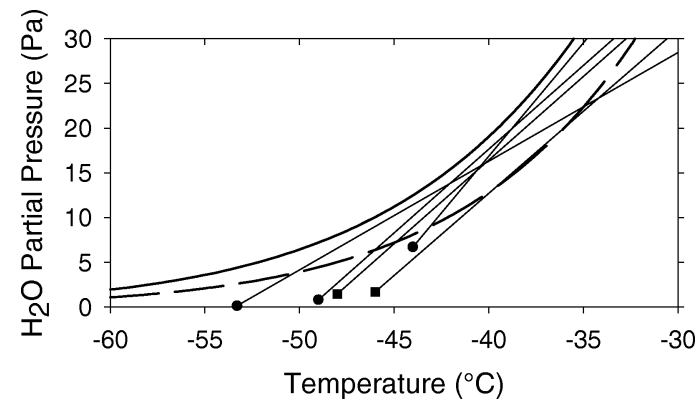

Figure 4. Subset of cases from figures 3(c), where no contrails have been observed but where the mixing line crosses the ice saturation curve. 


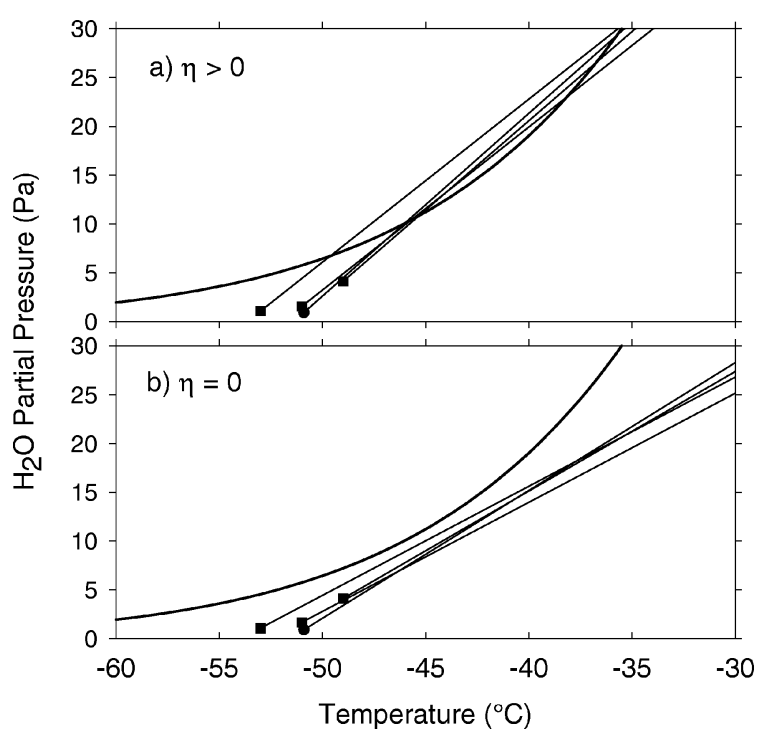

Figure 5. Subset of cases from figures 3(a), where contrails have been observed and where the mixing line crosses the liquid saturation curve if computed for $\eta>0$ (a), but does not so if computed for $\eta=0$ (b).

$(\eta=0)$, gives wrong results for the threshold temperature value.

Other observational studies [21,30,38] generally support the extended Schmidt-Appleman criterion, but provide less stringent validation tests because of missing or less precise data, in particular for ambient temperature and humidity and aircraft/engine performance at the location and time of contrail observations.

\subsection{Measured ratio of temperature and concentration increases in plumes}

The measurements cited above did measure $T$ and $q$ in the ambient air, but not the excess values $\Delta T$ and $\Delta q$ in the exhaust plume above ambient values. Hence they cannot be used to experimentally verify that the ratio $\Delta T / \Delta q=(1-\eta) Q /\left(c_{\mathrm{p}} E I_{\mathrm{H}_{2} \mathrm{O}}\right)$ is the lower the higher $\eta$.

Measurements of $\Delta T$ and $\Delta q$ have been performed in the exhaust plume of the ATTAS aircraft during SULFUR 3, with computed efficiency $\eta=0.17$, for plume ages of 0.5 to $17 \mathrm{~s}$ [34]. The data, see figure 6 , are consistent with the expected ratio. Large $\Delta T$-values correspond to young plumes with strong jet flows. Here the ratio $\Delta T / \Delta q$ may be smaller than later because part of the kinetic energy has still to be converted to internal energy. The measured $\Delta T$ values are systematically smaller than the normalised values for $\Delta q$. The ratio between the two values is close to the value $(1-\eta)$ supporting the theory. However, the accuracy of the measured data may not be sufficient to determine the effective factor $(1-\eta)$ from the data reliably. This is

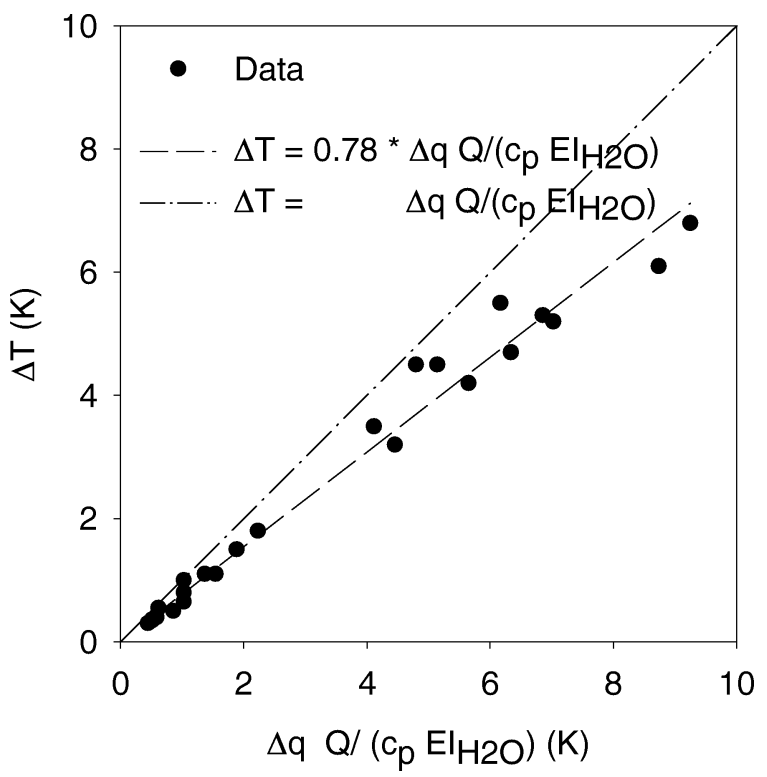

Figure 6. Measured temperature difference $\Delta T$ versus measured water vapour mass concentration increase $\Delta q$, normalised to an equivalent temperature by means of multiplication with combustion heat $Q$, specific heat capacity $c_{\mathrm{p}}$, and emission index $E I_{\mathrm{H}_{2} \mathrm{O}}$, as obtained by measurements with the Falcon in the plume of the ATTAS aircraft during the SULFUR 5 experiment ([34], data provided by R. Baumann). The diagonal and a least square fit line are indicated showing that the data would be best fit for $\eta=(1-0.78)=0.22$. The computed overall efficiency of the ATTAS aircraft is 0.17 .

the case in particular for plume ages larger than $4 \mathrm{~s}$, where the temperature differences are less than $1 \mathrm{~K}$, and where small random changes of ambient temperature cause large uncertainties in determining $\Delta T$ and also $\Delta q$.

Like water vapour, carbon dioxide also gets emitted from combustors burning kerosene into the engine plume independently of engine efficiency and undergoes the same mixing as heat. Values of temperature increase $\Delta T$ and carbon dioxide increase $\Delta \mathrm{CO}_{2}$ in young exhaust plumes were measured simultaneously within the SNIF campaign [1], and were used to test the $\eta$-dependence of the $\Delta T / \Delta \mathrm{CO}_{2}$ ratio. However, the data scatter strongly around a mixing line and do not provide a significant test of the theory because the instruments measuring the plume properties used inlets at different positions on the fuselage of the measuring aircraft.

\subsection{Direct test of the $\eta$-dependence}

For a direct test of the theory, a formation flight of two different large jet aircraft was arranged, wing by wing, during an ascent and a descent of the aircraft. Contrail formation and ambient conditions were observed simultaneously from a research aircraft. The two contrail forming aircraft were (i) a Boeing B707 equipped with four jet engines of type JT3D-3B with bypass-ratio of 1.4 and 


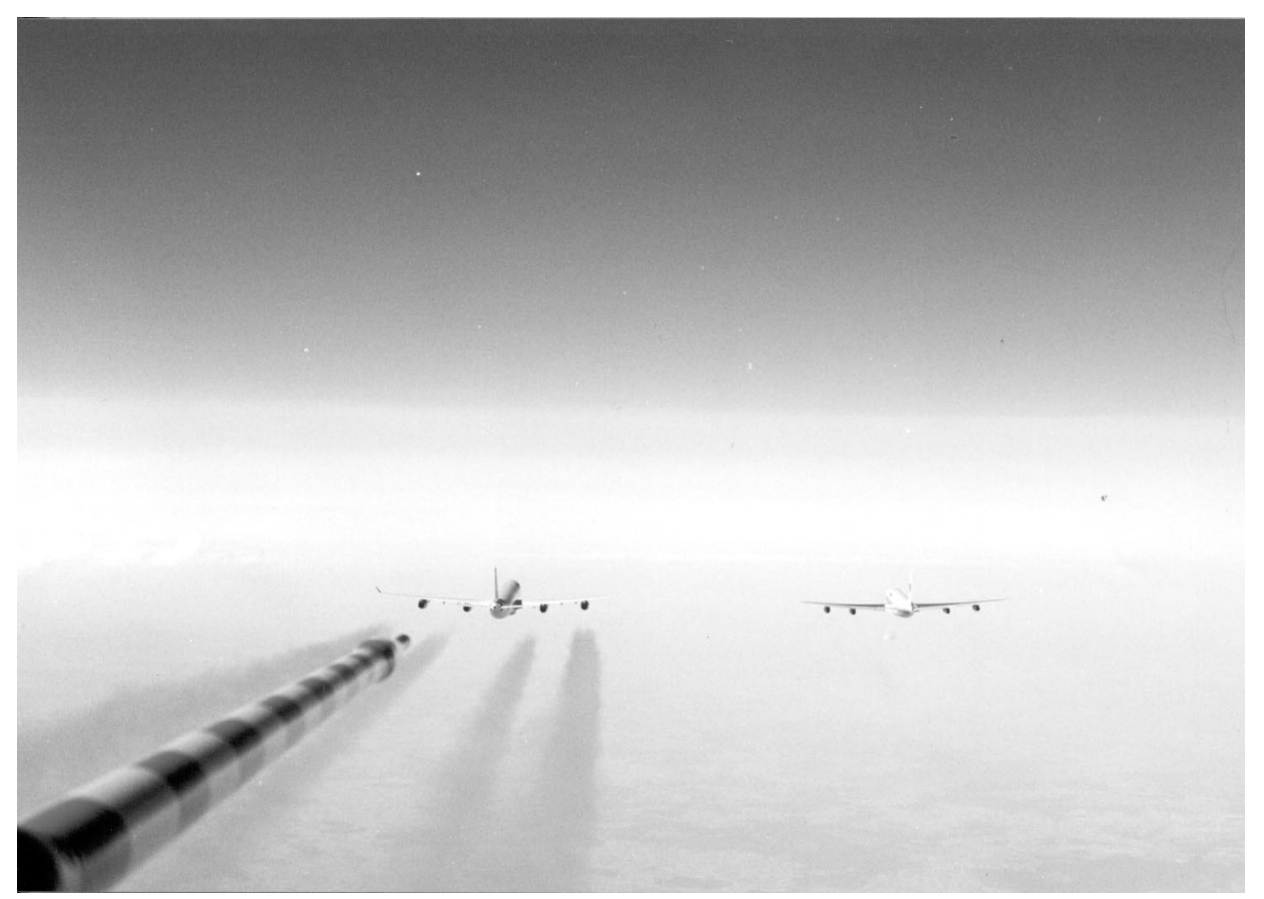

Figure 7. Photo of an Airbus A340 with contrails (left) and a Boeing B707 without contrails (right) at $10.5 \mathrm{~km}$ altitude taken from the Falcon cockpit [36].

(ii) an Airbus A340-300 with four jet engines of type CFM56-5C4 with bypass-ratio of 6.8. Ambient conditions were measured and the contrail formation was observed from a research aircraft flying less than $1 \mathrm{~km}$ behind the two contrail forming aircraft. As documented in several photos, an altitude range exists in which the A340 causes contrails while the B707 causes none. Figure 7 shows an example as taken during descent. We clearly see the four contrails forming from the four engines of the A340 while the B707 is seen flying without contrails. The details of these observations and their interpretation with an engine cycle model are described by Schumann et al. [36]. The observations support directly the validity of the theory: The aircraft with more efficient engines causes contrails while the aircraft with less efficient engines causes none during flight at the same altitude under very similar conditions.

\section{Conclusions}

The thermodynamic analysis, which is the result of first-principle arguments, implies that aircraft and engines, performing with a higher overall propulsion efficiency release a smaller fraction of the combustion heat during cruise into the exhaust plume, and hence cause plume conditions which during mixing reach higher relative humidity for the same ambient temperature and hence form contrails also at higher ambient temperatures.
Hence aircraft will form contrails more frequently when using more fuel efficient engines. The theory implies that the ratio of $\Delta T / \Delta q$ in exhaust plumes remote from the engine is the lower the higher $\eta$.

This effect can be verified only during flight and not on test rigs (at the ground) because fixed engines produce thrust $F$ but do not perform work $F V$ because of zero speed $V$.

A large set of observations of aircraft flying with and without contrails and with measured ambient conditions has been compiled. The observations are consistent with the extended Schmidt-Appleman criterion which includes the $\eta$-effect. The data also show that liquid saturation is required for contrail formation. Some observed contrails cannot be explained with the SchmidtAppleman criterion when the $\eta$-effect is ignored.

Existing measurements in plumes of temperature and concentration increases are consistent with the theory, but the accuracy of existing data may not be high enough for a rigorous test.

A recent case study with two airliners with different engines, with details reported in a parallel publication [36], shows that an altitude range exists in which the aircraft with high overall propulsion efficiency causes contrails while the aircraft with lower efficiency causes none, as predicted by the theory.

The analysis of contrail impact on radiative forcing performed so far $[7,18,20]$ implies that future aircraft with higher propulsion efficiencies cause more contrails 
and hence more warming of the atmosphere. However, these analysis methods are only first order estimates. They were performed for fixed fuel consumption scenarios. Hence they do not account for savings in fuel consumption and carbon dioxide emissions when engines and aircraft get improved for fixed traffic. The relative importance of carbon dioxide emissions, contrails and other short-lived effects depends on the development of traffic and emissions with time, because contrails impact radiative heating of the atmosphere immediately while carbon dioxide emissions impact the atmosphere only after long periods of accumulation in the atmosphere $[10,16$, 26]. Moreover the analysis uses fuel consumption scenarios and meteorological analysis data but does not account for the yet unknown details of induced contrail-cirrus as a function of aircraft properties, ambient conditions, and particle emissions. Understanding of the induced cirrus is certainly more important now than further experiments on contrail threshold conditions. As stated in the IPCC report, our limited scientific understanding of "the influence of contrails and aerosols on cirrus clouds" remains one of the "key areas of scientific uncertainty that limit our ability to project aviation impacts on climate".

\section{References}

[1] Anderson B.E., Cofer III W.R., McDougal D.S., Air Force F-16 aircraft engine aerosol emissions under cruise altitude conditions, NASA/TM-1999-209102, Langley Research Center, Hampton, Va., 1999, p. 52.

[2] Appleman H., The formation of exhaust contrails by jet aircraft, B. Am. Meteorol. Soc. 34 (1953) 14-20.

[3] Busen R., Schumann U., Visible contrail formation from fuels with different sulfur contents, Geophys. Res. Lett. 22 (1995) 1357-1360.

[4] Coleman R.F., A new formulation for the critical temperature for contrail formation, J. Appl. Meteorol. 35 (1996) 2270-2282.

[5] Cumpsty N., Jet Propulsion, Cambridge Univ. Press, Cambridge, 1997.

[6] Döpelheuer A., Lecht M., Influence of engine performance on engine characteristics, in: Gas Turbine Engine Combustion, Emissions and Alternative Fuels, The Research and Technology Organisation (RTO) of NATO, Neuilly-sur-Seine, France, Meeting Proceedings, ISBN 92-837-009-0, RTO-MP-14, 1999, pp. 20-1-20-11.

[7] Fahey D.W., Schumann U., Aviation-produced aerosols and cloudiness, in: Penner J.E., Lister D.H., Griggs D.J., Dokken D.J., McFarland M. (Eds.), Aviation and the Global Atmosphere, A Special Report of IPCC (Intergovernmental Panel on Climate Change), Cambridge Univ. Press, Cambridge, UK, 1999, pp. 65-120.

[8] Ferris P.D., The formation and forecasting of condensation trails behind modern aircraft, Meteorol. Appl. 3 (1996) 301-306.

[9] Gierens K., Sausen R., Schumann U., A diagnostic study of the global distribution of contrails, Part II: Future air traffic scenarios, Theor. Appl. Climatol. 63 (1999) 1-9.
[10] IPCC (Intergovernmental Panel on Climate Change), Aviation and the Global Atmosphere, in: Penner J.E., Lister D.H., Griggs D.J., Dokken D.J., McFarland M. (Eds.), Cambridge Univ. Press, Cambridge, UK, 1999.

[11] Jensen E.J., Toon O.B., Kinne S., Sachse G.W., Anderson B.E., Chan K.R., Twohy C.H., Gandrud B., Heymsfield A., Miake-Lye R.C., Environmental conditions required for contrail formation and persistence, J. Geophys. Res. 103 (1998) 3929-3936.

[12] Kärcher B., Aviation-produced aerosols and contrails, Surv. Geophys. 20 (1999) 113-167.

[13] Kärcher B., Busen R., Petzold A., Schröder F.P., Schumann U., Jensen E.J., Physicochemistry of aircraftgenerated liquid aerosols, soot, and ice particles, 2, Comparison with observations and sensitivity studies, J. Geophys. Res. 103 (17) (1998) 129-147.

[14] Knollenberg R.G., Measurements of the growth of ice budget in a persisting contrail, J. Atmos. Sci. 29 (1972) 1367-1374.

[15] Madden P., Development of emissions methodology to account for the global atmospheric impact of aviation, Inst. Mech. Eng., London, C545/063/98 (1998) 251-269.

[16] Marquart, S., Sausen R., Ponater M., Grewe V., Estimate of the climate impact of cryoplanes, Report No. 129, Institute of Atmospheric Physics, DLR, 2000.

[17] Mazin I.P., Aircraft condensation trails, Iz. Atmos. Oceanic Phys. 32 (1996) 1-13.

[18] Meerkötter R., Schumann U., Doelling D.R., Minnis P., Nakajima T., Tsushima Y., Radiative forcing by contrails, Ann. Geophys. 17 (1999) 1080-1094.

[19] Miake-Lye R.C., Martinez-Sanchez M., Brown R.C., Kolb C.E., Plume and wake dynamics, mixing and chemistry behind an HSCT aircraft, J. Aircraft 30 (1993) 467479.

[20] Minnis P., Schumann U., Doelling D.R., Gierens K.M., Fahey D.W., Global distribution of contrail radiative forcing, Geophys. Res. Lett. 26 (1999) 1853-1856.

[21] Moss S.J., The testing and verification of contrail forecasts using pilot observations from aircraft, Meteorol. Appl. 6 (1999) 193-200.

[22] Ovarlez J., van Velthoven P., Comparison of water vapor measurements with data retrieved from ECMWF analysis during the POLINAT experiment, J. Appl. Meteorol. 36 (1997) 1329-1335.

[23] Peters J.L., New Techniques for Contrail Forecasting, Air Weather Service, Scott Air Force Base, Illinois, AWS/TR93/001, AD-A269 686, 1993, p. 31.

[24] Petzold A., Busen R., Schröder F.P., Baumann R., Kuhn M., Ström J., Hagen D.E., Whitefield P.D., Baumgardner D., Arnold F., Borrmann S., Schumann U., Near field measurements on contrail properties from fuels with different sulfur content, J. Geophys. Res. 102 (1997) 29867-29881.

[25] Sadovnikov A.V., Reasons for the production of aircraft trail formation, in: Tr. Voennogo Gidrometeorol. Fakul'teta, Trans. Military Hydrometeorol. Departm., No. 11, 1955, pp. 44-75.

[26] Sausen R., Schumann U., Estimates of the climate response to aircraft $\mathrm{CO}_{2}$ and $\mathrm{NO}_{x}$ emissions scenarios, Climatic Change 44 (2000) 27-58. 
[27] Sausen R., Gierens K., Ponater M., Schumann U., A diagnostic study of the global distribution of contrails: Part I: Present day climate, Theor. Appl. Climatol. 61 (1998) 127-141.

[28] Schmidt E., Die Entstehung von Eisnebel aus den Auspuffgasen von Flugmotoren, in: Schriften der Deutschen Akademie der Luftfahrtforschung, Verlag R. Oldenbourg, München/Berlin, Heft 44, 1941, pp. 1-15.

[29] Schrader M.L., Calculations of aircraft contrail formation critical temperatures, J. Appl. Meteorol. 36 (1997) 17251728.

[30] Schrader M.L., Meyer W.D., Weaver C.L., Comments on 'A reexamination of the formation of exhaust condensation trails by jet aircraft', J. Appl. Meteorol. 36 (1997) 623-626.

[31] Schumann U., On conditions for contrail formation from aircraft exhausts, Meteorol. Z. 5 (1996) 4-23.

[32] Schumann U., Ström J., Busen R., Baumann R., Gierens K., Krautstrunk M., Schröder F.P., Sting1 J., In situ observations of particles in jet aircraft exhausts and contrails for different sulfur containing fuels, J. Geophys. Res. 101 (1996) 6853-6869.
[33] Schumann U., Dörnbrack A., Dürbeck T., Gerz T., Largeeddy simulation of turbulence in the free atmosphere and behind aircraft, Fluid Dyn. Res. 20 (1997) 1-10.

[34] Schumann U., Schlager H., Arnold F., Baumann R., Haschberger P., Klemm O., Dilution of aircraft exhaust plumes at cruise altitudes, Atmos. Environ. 32 (1998) 3097-3103.

[35] Schumann U., Schlager H., Arnold F., Ovarlez J., Kelder H., Hov Ø., Hayman G., Isaksen I.S.A., Staehelin J., Whitefield P.D., Pollution from aircraft emissions in the North Atlantic flight corridor: Overview on the POLINAT projects, J. Geophys. Res. 105 (2000) 3605-3631.

[36] Schumann U., Busen R., Plohr M., Experimental test of the influence of propulsion efficiency on contrail formation, J. Aircraft (2000) submitted.

[37] Sonntag D., Advancements in the field of hygrometry, Meteorol. Z. 3 (1994) 51-66.

[38] Walters M.K., Shull J.D., Asbury III R.P., A comparison of exhaust condensation trail forecast algorithms at low relative humidity, J. Appl. Meteorol. 39 (2000) 80-91. 